\title{
STANDARISASI SAPI BALI PEJANTAN DALAM MEMPERCEPAT PERBAIKAN MUTU GENETIK DAN PENINGKATAN PRODUKSI UNTUK MENJAGA KETAHANAN PANGAN NASIONAL
}

\section{STANDARDIZATION OF BALI BOTTLE IN ACCELERING GENETIC QUALITY IMPROVEMENTS AND INCREASING PRODUCTION TO MAINTAIN NATIONAL FOOD SECURITY}

\author{
Ni Putu Sukanteri ${ }^{1 *}$, Mikhael Rahmat Ranta $^{2}$, Putu Fajar Kartika Lestari ${ }^{3}$, \\ I Made Budiasa ${ }^{4}$ \\ ${ }^{1,2,3,4}$ Program Studi Agribisnis, Universitas Mahasaraswati, Kota Denpasar, Indonesia \\ *Email Penulis Korespondensi: putusukanteri@unmas.ac.id
}

\begin{abstract}
Abstrak
Studi ini bertujuan untuk mengetahui standarisasi sapi Bali pejantan di Unit Pelaksana Teknis (UPT) Balai Inseminasi Buatan Provinsi Bali. Data primer diperoleh dengan teknis survey, wawancara, dan pelatihan kerja, sedangkan data sekunder diperoleh melalui catatan hasil pengukuran parameter pada sapi Bali pejantan pada bulan Mei 2021 di Unit Pelaksana Teknis (UPT) Balai Inseminasi Buatan Daerah Provinsi Bali. Variabel yang diamati dalam kegiatan penelitian ini antara lain: asal usul pejantan, kondisi kesehatan pejantan, penampilan kualitatif berupa warna bulu, dan bentuk kepala, serta kuantitatif individu berupa tinggi gumba (TG), panjang badan (PB), lingkar dada (LD), lingkar scrotum (LSC), dan berat badan (BB). Hasil pengamatan menunjukkan bahwa asal usul pejantan sudah terekording, kondisi kesehatan pejantan sudah baik, penampilan kualitatif sudah sesuai SNI penampilan kuantitatif individu pejantan sesuai SNI. Hasil kegiatan menunjukkan bahwa secara umum sapi Bali pejantan di UPT BIBD Provinsi Bali memenuhi standar SNI yaitu asal usul pejantan jelas, kondisi kesehatan pejantan secara umum dalam keadaan sehat, penampilan kualitatif dan kuantitatif individu pejantan sesuai SNI.
\end{abstract}

Kata Kunci : Standarisasi, Sapi Bali Pejantan.

\begin{abstract}
This study aims to determine the standardization of male Bali cattle in the Technical Implementation Unit (UPT) of the Bali Province Artificial Insemination Center. Primary data was obtained by technical surveys, interviews, and job training, while secondary data was obtained through records of parameter measurements on male Bali cattle in May 2021 at the Technical Implementation Unit (UPT) of the Regional Artificial Insemination Center of Bali Province. The variables observed in this research activity included: the origin of the male, the male's health condition, qualitative appearance in the form of coat color, and head shape, as well as individual quantitative in the form of gumba height (TG), body length (PB), chest circumference (LD), scrotal circumference (LSC), and body weight (BB). The results of the observations showed that the origin of the male had been tracked, the health condition of the male was good, the qualitative appearance was in accordance with SNI. The quantitative appearance of the individual males was in accordance with SNI. The results of the activity show that in general the male Bali cattle at UPT BIBD Bali Province meet the SNI standards, namely the origin of the male is clear, the male health condition is generally in good health, the qualitative and quantitative appearance of individual males according to SNI.
\end{abstract}

Keywords : Standardization, Bal Cow Stud.

Sukanteri, N.P., Ranta, M.R., Lestari, P.FK., dan Budiasa, I.M. 


\section{PENDAHULUAN}

Sapi Bali merupakan salah satu plasma nutfah nasional yang perlu dipertahankan kelestariannya. Sapi Bali memiliki keunggulan karakteristik seperti fertilitas tinggi, lebih tahan terhadap kondisi lingkungan yang kurang baik, cepat beradaptasi apabila dihadapkan dengan lingkungan yang baru, cepat berkembang biak, dan kandungan lemak karkas rendah (Harjosubroto, 1994). Sapi Bali memegang peranan penting sebagai sumber daging local di Bali membutuhkan banyak sapi yang diproduksi dengan menjaga sapi Bali tidak punah.

Tingginya permintaan sapi Bali belum diimbangi dengan usaha-usaha pembibitan atau hal-hal yang berkaitan dengan perbaikan mutu genetik ternak. Ternak sapi Bali memiliki masalah utama dalam upaya pengembangannya yaitu rendahnya kualitas bibit yang ditengarai akibat dari kejadian inbreeding (silang dalam) atau manajemen pemeliharaan. ("Pertumbuhan Dimensi Tinggi Tubuh Pedet Sapi Bali," 2014). Warwick et al. (1983) menyatakan bahwa perkawinan silang dalam pada ternak sapi potong mengakibatkan penurunan berat badan sekitar 2,5-5,0 $\mathrm{kg}$ setiap kenaikan $10 \%$ silang dalam.

Usaha di bidang peternakan, khususnya ternak sapi Bali membutuhkan perhatian khusus dalam kaitannya dengan upaya mempertahankan dan meningkatkan populasi sapi Bali. Dalam menanggulangi masalah itu dibutuhkan teknologi tepat yang bisa diterapkan secara mudah dan efisien.(Hakim, Suyadi, Nuryadi, Susilawati, \& Nurgiartiningsih, 2017). Salah satu teknologi yang bisa digunakan yaitu inseminasi buatan. Inseminasi Buatan (IB) merupakan salah satu bentuk bioteknologi dalam bidang reproduksi yang memungkinkan manusia untuk mengawinkan hewan betina tanpa perlu seekor pejantan utuh (Kartasudjana, 2001). Namun pada perkembangan lebih lanjut, program IB tidak hanya mencakup pemasukan semen ke dalam saluran reproduksi betina, tetapi juga menyangkut seleksi dan pemeliharaan pejantan (Sugoro, 2009). Kondisi tubuh berpengaruh sangat nyata terhadap produksi semen segar (volume), konsentrasi spermatozoa, dan berpengaruh nyata terhadap produksi semen beku Pejantan dengan SKT optimum memiliki produksi semen segar, konsentrasi spermatozoa, dan produksi semen beku tertinggi kemudian diikuti oleh SKT gemuk dan sedang (Mappanganro, 2020),

Di UPT Balai Inseminasi Buatan Provinsi Bali merupakan balai produksi semen beku sapi bali. Dalam produksi semen beku tersebut, UPT BIB Provinsi Bali harus menggunakan standar agar menghasilkan kualitas dan kuantitas semen beku yang baik. Dengan adanya SNI, dimaksudkan sebagai upaya untuk meningkatkan jaminan mutu ternak. Yang harus diperhatikan dalam SNI yaitu asal usul pejantan, kondisi kesehatan pejantan, penampilan kualitatif berupa warna bulu, dan bentuk kepala, serta kuantitatif individu berupa tinggi gumba (TG), panjang badan (PB), lingkar dada (LD), lingkar scrotum (LSC), dan berat badan (BB).

Mengingat pentingnya penerapan SNI tersebut di UPT BIB Daerah Provinsi Bali, maka perlu dilakukan pengkajian agar mengetahui stansarisasi yang digunakan sehingga dapat meningkatkan kualitas dan kuantias semen yang baik. Tujuan Penelitian ini adalah untuk mengetahui asal usul sapi Bali pejantan, kondisi kesehatan pejantan, penampilan dan mengukur kuantitatif individu berupa tinggi gumba (TG), panjang badan (PB), lingkar dada (LD), lingkar scrotum (LSC), dan berat badan (BB). 


\section{METODE PENELITIAN}

\section{Tempat dan Waktu Kegiatan}

Penelitian dilaksanakan di Unit Pelaksana Teknis (UPT) Balai Inseminasi Buatan Daerah Provinsi Bali. Pelaksanaan selama 1 bulan mulai tanggal 17 Mei-17 Juni 2021

\section{Metode Pelaksanaan}

Metode mengumpulkan data yaitu observasi, wawancara, dan studi pustaka. Metode observasi dilaksanakan dengan praktek dan pengamatan langsung mengenai kondisi ternak. Metode wawancara dilaksanakan dengan melaksanakan tanya-jawab dengan salah satu staff di UPT Balai Inseminasi Buatan di Baturiti mengenai data recording pada sapi pejantan.

Metode studi pustaka dilaksanakan dengan mempelajari pustaka yang bersumber dari buku, jurnal dan data di internet mengenai standar SNI sapi Bali. Data yang dikumpulkan data primer mengenai ukuran kuantitatif individu berupa kondisi kesehatan pejantan, penampilan kualitatif berupa warna bulu, dan bentuk kepala, serta kuantitatif individu berupa tinggi gumba (TG), panjang badan (PB), lingkar dada (LD), lingkar scrotum (LSC), dan berat badan (BB).

\section{HASIL DAN PEMBAHASAN}

\section{Penampilan Fisik Sapi Bali untuk Pejantan}

Ada beberapa hal yang perlu diperhatikan dalam pemilihan calon indukan jantan yaitu

1. Penampilan luar

Calon induk betina dan induk pejantan harus dipilih yang memiliki penampilan luar yang baik (Guntoro, 2002). Biasanya, Sapi Bali yang memiliki penampilan luar baik akan mempengaruhi produktivitas dan mutu anak yang dihasilkan. Untuk menilai penampilan luar Sapi Bali dapat dilihat dari kondisi umum dan kondisi khusus.

1) Kondisi umum

Adapun penampilan luar sapi yang perlu diperhatikan dalam pemilihan calon indukan adalah :

a. Sapi dalam keadaan sehat dan tidak cacat

b. Sapi memiliki mata cerah dan kulit mengkilat (tidak kusam)

c. Sapi bergerak lincah dan nafsu makannya baik

d. Sapi memiliki leher panjang dan besar

e. Sapi memiliki tubuh panjang, berbentuk balok (segi empat), dan dada dalam

f. Sapi memiliki kaki besar, tegak, dan kokoh

g. Sapi memiliki pertumbuhan tubuh yang kompak/serasi

h. Sapi memiliki warna kulit dan bulu khas Sapi Bali (hitam legam untu sapi jantan dan merah untuk sapi betina).

2) Kondisi khusus

Berdasarkan ketentuan kontes dan pameran ternak nasional, yang termasuk dalam "statistik vital" pada ternak sapi meliputi ukuran tinggi gumba, panjang badan, lingkar dada, lebar dada, dalam dada, lebar punggung, lebar pinggul, panjang pingul, panjang kepala, lebar kepala, berat badan dan umur sapi. Ukuran "statistik vital" dari organ tertentu jika dikaitkan dengan umur sapi akan menggambarkan keharmonisan perkembangan tubuh dan produktivitas (pertumbuhan). Karena itu, pertumbuhan organ-organ tertentu berhubungan dengan berat badan. 
Tabel 1. Ukuran Minimum "Statistik Vital” Sapi Bali Induk/ Calon Induk

\begin{tabular}{clcc}
\hline & & \multicolumn{2}{c}{ Umur } \\
\cline { 3 - 4 } No. & Parameter Tubuh & Muda $(2-3,5$ & Dewasa $(4-8$ \\
& & Th) & Th) \\
\hline 1. & Tingi gumba $(\mathrm{cm})$ & 105 & 123 \\
2. & Panjang badan $(\mathrm{cm})$ & 116 & 140 \\
3. & Lingkaran dada $(\mathrm{cm})$ & 162 & 170 \\
4. & Berat badan $(\mathrm{kg})$ & 325 & 375 \\
\hline
\end{tabular}

Sumber: Anonim (1978)

Adapun ukuran minimum "statistik vital" bagi sapi induk/ calon induk dan sapi pejantan/calon pejantan dapat dilihat pada Tabel 1.

Bentuk ambing yang dipilih adalah yang berukuran besar, ukuran putingnya normal dan jumlah genap (empat buah), serta bentuk tubuhnya simetris. Kondisi putting dan ambing erat kaitannya dengan produktivitas susu yang sangat penting bagi pertumbuhan anak sapi yang dihasilkan (Guntoro, 2002).

Kondisi tubuh sapi dapat diklasifikasikan menjadi tiga katagori yakni gemuk, sedang dan kurus. Calon induk betina ataupun jantan dipilih sapi yang memiliki katagori tubuh sedang hingga gemuk disebabkan karena calon induk betina akan lebih banyak berpeluang untuk bergerak dan produktivitasnya tidak diukur dari tambahan berat badan, melainkan dari daya reproduksinya. Untuk sapi bakalan yang akan digemukkan, sebaiknya dipilih yang memiliki kategori kurus hingga sedang (Guntoro, 2002).

\section{Profil UPT Balai Inseminasi Buatan Daerah Provinsi Bali}

Pemerintah Provinsi Bali mempunyai kebijakan untuk mempertahankan daerah Bali sebagai sumber Sapi Bali murni yang merupakan plasma nutfah, maka upaya pengembangan dan pemurnian terus dilakukan untuk peningkatan mutu genetik melalui penerapan bioteknologi IB. UPT dibangun untuk memberikan pelayanan IB secara optimal dengan salah satu tugas pokoknya memproduksi semen beku Sapi Bali murni secara kontinyu dan berkualitas.

Visi UPT BIBD Dinas Peternakan Provinsi Bali adalah terwujudnya peningkatan mutu genetik ternak berbasis sumber daya lokal. UPT BIBD menetapkan enam misi yang harus dilaksanakan sebagai berikut: memproduksi semen beku sapi Bali murni, menyiapkan bibit unggul sapi Bali, mengembangkan bioteknologi yang efektif dan efesien, meningkatkan kemampuan sumber daya manusia dibidang bioteknologi, menyediakan sarana dan prasarana dan melaksanakan pelayanan IB dan melestarikan plasma nulfah sapi bali dan sumberdaya peternakan lainnya. BIBD Provinsi Bali ini fokus ke dua bagian yaitu bagian produksi sperma sapi dan bagian produksi sperma babi.

\section{Asal usul Pejantan Sapi Bali}

Sapi Bali merupakan sapi potong asli Indonesia dan merupakan hasil domestikasi dari banteng (bibos banteng) (Hardjosubroto, 1994) dan merupakan sapi asli Pulau Bali ( Pane, 1989)

Ditinjau dari sistematika ternak, Sapi Bali masuk familia bovidae, genus bos dan sub-genus bovine, yang termasuk dalam sub-genus tersebut adalah bibos gaurus, bibos frontalis dan bibos sondaicus (Hardjosubroto, 1994), Sapi Bali (Bos-Bibos Banteng) yang spesies liarnya adalah banteng termasuk familia bovidae, genus bos dan sub- 
genus bibos (Williamson dan Payne 1978).

Sapi Bali mempunyai ciri-ciri khusus antara lain warna bulu merah bata, tetapi yang jantan dewasa berubah menjadi hitam (Hardjosubroto, 1994). Satu karakter lain yakni perubahan warna sapi jantan kebirian dari warna hitam kembali pada warna semula yakni coklat muda keemasan yang diduga karena makin tersedianya hormon testosteron sebagai hasil produk testes (Aalfs, 1934 dalam Darmaja, 1980).

Hardjosubroto (1994) menyatakan bahwa ada tanda-tanda khusus yang harus dipenuhi sebagai Sapi Bali murni, yaitu warna putih pada bagian belakang paha, pinggiran bibir atas, dan pada paha kaki bawah mulai tarsus dan carpus sampai batas pinggir atas kuku, bulu pada ujung ekor hitam, bulu pada bagian dalam telinga putih, terdapat garis belut (garis hitam) yang jelas pada bagian atas punggung, bentuk tanduk pada jantan yang paling ideal disebut bentuk tanduk silak congklok yaitu jalannya pertumbuhan tanduk mula-mula dari dasar sedikit keluar lalu membengkok keatas, kemudian pada ujungnya membengkok sedikit keluar. Pada yang betina bentuk tanduk yang ideal yang disebut manggul gangsa yaitu jalannya pertumbuhan tanduk satu garis dengan dahi arah kebelakang sedikit melengkung kebawah dan pada ujungnya sedikit mengarah kebawah dan kedalam, tanduk ini berwarna hitam.

UPT BIBD Dinas Peternakan Provinsi Bali telah mencatat asal usul ternak pejantan sapi bali yang ada di sana. Hal ini ditujukan untuk menghindari kasus inbreeding dalam proses IB yang akan dilakukan.

Tabel 2. Nama -Nama Pejantan Sapi Bali di UPTD Inseminasi Buatan Daerah Bali

\begin{tabular}{lll}
\hline No & Nama Bull & Asal \\
\hline 1 & Badilawa & Badung \\
2 & Bangkardi & Bangli \\
3 & Bangtidar & Bangle \\
4 & Blandar & Bengli \\
5 & Budaparta & Buleleng \\
6 & Bugamanta & Buleleng \\
7 & Bulbakanta & Buleleng \\
8 & Buwana Merta & Buleleng \\
9 & tamara & Tabanan \\
\hline
\end{tabular}

Sumber: Data skunder BIBD Provinsi Bali, 2021

\section{Manajemen Penggemukan Sapi Bali Pejantan}

Pertumbuhan Sapi Bali yang baik dan sehat, sitem dan tata laksana pemeliharaanya pun harus baik. Hal ini tergantung pada maksud dan tujuan pemeliharaan ternak tersebut, baik sebagai ternak kerja, ternak potong, bibit dan penyediakan indukan jantan.

Sistem pemeliharaan ternak pada umumnya dengan sistem semi intensif $(45,45 \%)$ dengan pakan yang diberikan adalah hijauan dengan merumput ditambah hijauan hasil pemotongan $(47,73 \%)$ (R. A. Putra \& Hendrita, 2019). Berbeda dengan pemeliharaan Sapi Bali sebagai pemacak pada umumnya menggunakan tiga sistem yaitu sisten intensif, semi intensif dan ekstensif. Perbedaan dari ketiga sistem pemeliharaan tersebut terletak pada cara pemberian pakan, tata laksana pemeliharaan dan perawatan sapi. Pemeliharaan sapi secara intensif biasanya dilakukan oleh perusahaan dalam skala besar dan dilakukan untuk tujuan tertentu, misalnya untuk penggemukan. Pemberian pakan telah menggunakan pakan konsentrat dan disesuaikan dengan kebutuhan sapi sehingga kebutuhan gizi bagi sapi yang dipelihara secara intensif 
terpenuhi. Sapi Bali yang dipelihara secara intensif disediakan kandang yang memadai dan sanitasi serta pemeriksaaan kesehatan sapi dilakukan secara kontinyu(Nuraini, Sunarto, Widyas, Pramono, \& Prastowo, 2020).

Pada sistem pemeliharaan semi intensif, sapi yang dipelihara diikat dibawah pohon yang rimbun dan diberi pakan secara cut and carry (Zero Grassing). Sapi sepenuhnya diawasi oleh peternak, terutama dalam hal sanitasi kandang/lingkungan, pakan dan obat- obatan. Kegiatan pemeliharaan Sapi Bali yang paling penting adalah pemilihan bibit, pembuatan kandang untuk tempat berlindung, pemberian pakan yang bergizi, pengawasan kesehatan dan usaha- usaha peningkatan produksi Sapi Bali dengan cara penggemukan pada UPTD Inseminasi Buatan Daerah Provinsi Bali dilakukan pemeliharaan secara intensif, komposisi konsentrat, dedak dan hijauan. Guna mempertahankan kesehatan sapi Bali pejantan agar menghasilkan semen yang berkualitas.

\section{Kondisi kesehatan pejantan Sapi Bali}

Lingkungan mempunyai pengaruh terhadap kondisi fisiologis sapi (Collier et al., 2006). Kondisi lingkungan dan heat stress pada sapi mengakibatkan sapi mengalami gangguan fungsi fisiologi dan penurunan imunitas (Mader et al., 2006).

Untuk menjaga kesehatan ternak,i UPT BIBD Provinsi Bali, ternak sapi bali pejantan dilakukan pemeriksaan kesehatan ternak secara rutin sebulan sekali, pemberian pakan sesuai kebutuhan ternak, sanitasi yang baik setiap hari, pemberian obat obatan secara tepat, exercise tiga kali dalam semiggu, dan perawatan ternak seperti pemotongan kuku secara teratur.

Dari perlakuan tersebut sehingga pada pemeriksaan kesehatan diketahui ternak sapi bali pejantan di UPT BIBD Provinsi Bali dalam kondisi sehat. Hal ini sesuai dengan standar SNI sapi bali bahwa persyaratan umum sapi bali yaitu sehat dan bebas dari penyakit hewan menular . (Besung, Sriyani, Sampurna, \& Agustina, 2016) menyatakan kesehatan ternak sapi dapat dilakukan dengan meningkatkan pengetahuan tentang formulasi pakan, identifikasi penyakit sejak dini penyakit dan perbibitan dari mutu yang baik. Menjaga ketahanan pangan nasional merupakan salah satu program yang ditunjang oleh perbanyakan sapi Bali melalui inseminasi buatan, mempercepat perbaikan mutu genetik, peningkatan produksi.

\section{Penampilan kualitatif dan kuantitatif individu pejantan sapi Bali}

Pengamatan kualitatif didapat bahwa sapi Bali pejantan keseluruhan yang ada di UPT BIBD Provinsi Bali yaitu memiliki warna hitam, kaki berwarna putih, pantat berwarna putih, ujung ekor hitam, tanduk hitam, serta memiliki kepala yang lebar. Hal tersebut sesuai dengan cici ciri sapi bali pejantan pada syarat SNI.

SNI menyebutkan bahwa standar sapi Bali pejantan dari persyaratan kualitatif yaitu memiliki warna bulu hitam, lutut kebawah putih, pantat putih berbentuk setengah bulan, ujung ekor hitam, tanduk tumbuh baik berwarna hitam, dan memiliki bentuk kepala lebar dengan leher kompak dan kuat(T. G. Putra, 2016).

Pengamatan kuantitatif dengan pengukuran tinggi gumba (TG) diukur dari bagian tertinggi gumba ke tanah mengikuti garis tegak lurus, panjang badan (PB) diukur dengan cara menarik garis horizontal dari tepi depan sendi bahu sampai ke tepi belakang tulang tapis, lingkar dada (LD) dengan cara melingkarkan pita ukur pada bagian dada belakang bahu, lingkar scrotum (LSC) dengan cara melingkarkan pita ukur pada bagian scrotum terbesar dalam keadaan sapi berdiri tegak, dan berat badan (BB) dengan cara menimbang ternak menggunakan timbangan. 
Sapi Bali menunjukkan tidak ada perbedaan bobot lahir pedet sapi dari pejantan berbeda, demikian juga terhadap bobot dan dimensi tubuh pedet sapi pra sapih hasil inseminasi buatan dari pejantan berbeda(M. \& Oka, 2020). Bobot lahir dan bobot sapih pada sistem tiga strata lebih berat daripada sistem tradisional, sedangkan lama kebuntingan tidak menunjukkan perbedaan nyata. Penampilan reproduksi sapi bali yang dipelihara dengan sistem pemeliharaan STS lebih baik dibandingkan dengan sistem pemeliharaan sistem tradisioanl (Pemayun Sentana Putra2, Putra, \& Puger, 2014).

Tabel 3. Distribusi Semen Beku Tahun 2020

\begin{tabular}{|c|c|c|c|c|}
\hline No & Nama Bull & $\begin{array}{c}\text { Non SNI } \\
\text { (Dosis) }\end{array}$ & SNI (Dosis) & Total (Dosis) \\
\hline 1 & Badilawa & & 9.920 & 9.920 \\
\hline 2 & Bangkardi & & 6.189 & 6.189 \\
\hline 3 & Bangtidar & & 9.873 & 9.873 \\
\hline 4 & Blandar & & 9.339 & 9.339 \\
\hline 5 & Budaparta & & 13.495 & 13.495 \\
\hline 6 & Bugamanta & & 4.495 & 4.495 \\
\hline 7 & Bulbakanta & & 18.891 & 18.891 \\
\hline 8 & Buwana Merta & & 17.741 & 17.741 \\
\hline \multirow[t]{2}{*}{9} & Tamara & & 5.938 & 5.938 \\
\hline & Grand Total & & 95.881 & 95.881 \\
\hline
\end{tabular}

Pada Tabel 3 menunjukkan bahwa dari Sembilan pejantan sapi Bali, terdapat dua ekor pejantan menghasilkan semen beku yang tinggi yaitu Billbalkanta dan Buwana Merta. Semesn beku yang dihasilkan meliputi volume (ml), warna, kekentalan, gerakan massa, konsentrasi (106 sel/ml), motilitas spermatozoa (\%), abnormalitas (\%), dan membran plasma utuh (\%). Hasil yang diperoleh dilakukan analisis dengan uji t. Hasil penelitian dapat disimpulkan bahwa musim tidak berpengaruh nyata $(\mathrm{P}>0,05)$ terhadap kualitas semen sapi bali di Balai Inseminasi Buatan Baturiti, Tabanan, Bali (Bebas, Gorda, \& Dada, 2021).

Tabel 4 . Persyaratan minimum kuantitatif sapi Bali pejantan berdasarkan SNI.

\begin{tabular}{|c|c|c|c|c|c|}
\hline \multirow{2}{*}{$\begin{array}{l}\text { Umur } \\
\text { (bulan) }\end{array}$} & \multirow{2}{*}{ Parameter } & \multirow{2}{*}{ Satuan } & \multicolumn{3}{|c|}{ Kelas } \\
\hline & & & I & II & III \\
\hline \multirow{4}{*}{$18-24$} & Tinggi pundak & $\mathrm{cm}$ & 115 & 110 & 105 \\
\hline & Panjang badan & $\mathrm{cm}$ & 125 & 120 & 119 \\
\hline & Lingkar dada & $\mathrm{cm}$ & 155 & 147 & 142 \\
\hline & Lingkar skrotum & $\mathrm{cm}$ & 25 & 25 & 25 \\
\hline \multirow{4}{*}{$>24-36$} & Tinggi pundak & $\mathrm{cm}$ & 127 & 120 & 113 \\
\hline & Panjang badan & $\mathrm{cm}$ & 133 & 124 & 115 \\
\hline & Lingkar dada & $\mathrm{cm}$ & 179 & 158 & 148 \\
\hline & Lingkar skrotum & $\mathrm{cm}$ & 26 & 26 & 26 \\
\hline
\end{tabular}

Sumber : SNI ternak sapi, 2008

Sapi yang dipelihara dengan sistem dan manajemen pakan yang seragam; dan umur pejantan memiliki korelasi positif dengan volume, sedangkan umur pejantan memiliki korelasi negatif dengan motilitas spermatozoa dan konsentrasi spermatozoa. 
Namun, secara umum baik volume semen, motilitas spermatozoa, dan konsentrasi spermatozoa masih dalam kisaran normal (Lestari, Saleh, \& Maidaswar, 2013). lingkar dada merupakan penduga bobot badan terbaik bagi calon pejantan sapi Bali. Pendugaan bobot badan calon pejantan sapi Bali umur 1,5 sampai 2 tahun sangat baik diaplikasikan pada peternakan tradisional di suatu wilayah dalam rangka memilih calon pejantan yang baik untuk wilayah tersebut (Zurahmah \& The, 2012).

Keseluruhan sapi Bali pejantan yang ada di UPT BIBD Provinsi Bali, hanya 9 sapi Bali pejantan yang diberikan sertifikasi produk penggunaan tanda SNI oleh Manajer Puncak Lembaga Sertifikasi Produk Benih dan Bibit Ternak, Direktorat Jenderal Peternkan dan Kesehatan Hewan.

Tabel 5. Sapi Bali Pejantan yang sudah memiliki sertifikat SNI dapat dilihat pada Tabel

Table sapi pejantan yang sudah memiliki sertifikat SNI

\begin{tabular}{cc} 
No & Nama Bull \\
\cline { 2 - 3 } 1 & Badilawa \\
2 & Bangkardi \\
3 & Bangtidar \\
4 & Blandar \\
5 & Budaparta \\
6 & Bugamanta \\
7 & Bulbakanta \\
8 & Buwana Merta \\
9 & Tamara \\
\hline
\end{tabular}

Sumber: Data skunder BIBD Provinsi Bali, 2021

\section{KESIMPULAN DAN SARAN}

\section{Kesimpulan}

Berdasarkan hasil penelitian dapat disimpulkan bahwa secara umum sapi bali pejantan di UPT BIBD Provinsi Bali memenuhi standar SNI yaitu asal usul pejantan sudah jelas, kondisi kesehatan pejantan secara umum dalam keadaan sehat, penampilan kualitatif dan kuantitatif individu pejantan sesuai SNI kecuali sapi bali pejantan dengan kode 11240 dengan lingkar scrotum $25 \mathrm{~cm}$ dibawah standar SNI yaitu $26 \mathrm{~cm}$ untuk usia $>24-36$ bulan.

\section{Saran}

Perlu mempertahankan status SNI yang telah diperoleh beberapa sapi bali pejantan di UPT BIBD Provinsi Bali, serta meningkatkan parameter syarat SNI pada seluruh sapi bali pejantan yang ada di UPT BIBD Provinsi Bali agar nantinya semua tersertifikasi SNI.

\section{DAFTAR PUSTAKA}

Bebas, W., Gorda, I. W., \& Dada, K. A. (2021). Pengaruh Musim Hujan dan Kemarau Terhadap Kualitas Semen Sapi Bali di Balai Inseminasi Buatan Baturiti, Tabanan, Bali. Buletin Veteriner Udayana. https://doi.org/10.24843/bulvet.2021.v13.i01.p16 
Besung, I. N. K., Sriyani, N. L. P., Sampurna, P., \& Agustina, K. K. (2016). Aplikasi Teknologi Pada Peternakan Sapi Bali. Jurnal Udayana Mengabdi.

Direktorat Budi Daya Ternak Ruminansia. 2010. Pedoman Teknis Pengembangan Usaha Integrasi Ternak Sapi dan Tanaman. Direktorat Budi Daya Ternak Ruminansia. Jakarta.

Hakim, L., Suyadi, S., Nuryadi, N., Susilawati, T., \& Nurgiartiningsih, A. (2017). Pengembangan Sistem Manajemen Breeding Sapi Bali. Sains Peternakan. https://doi.org/10.20961/sainspet.v6i1.4936

Lestari, S., Saleh, D. M., \& Maidaswar. (2013). Profil Kualitas Semen Segar Sapi Pejantan Limousin dengan Umur yang Berbeda di Balai Inseminasi Buatan Lembang Jawa Barat. Jurnal Ilmiah Peternakan.

M., D., \& Oka, A. A. (2020). Penampilan Pedet Sapi Bali Hasil Inseminasi Buatan Dari Pejantan Berbeda. Majalah Ilmiah Peternakan. https://doi.org/10.24843/mip.2020.v23.i01.p07

Mappanganro, R. (2020). Produksi Semen Segar (Volume dan Konsentrasi) dan Beku dari Sapi Pejantan dengan Skor Kondisi Tubuh (SKT) yang Berbeda. Jurnal Ilmu Dan Industri Peternakan (Journal of Animal Husbandry Science and Industry). https://doi.org/10.24252/jiip.v6i1.14444

Nuraini, D. M., Sunarto, S., Widyas, N., Pramono, A., \& Prastowo, S. (2020). Peningkatan Kapasitas Tata Laksana Kesehatan Ternak Sapi Potong di Pelemrejo, Andong, Boyolali. PRIMA: Journal of Community Empowering and Services. https://doi.org/10.20961/prima.v4i2.42574

Guntoro, S. 2002. Membudidayakan Sapi Bali. Penerbit Kanisius. Yogyakarta.

PemayunSentana Putra2, T. G. O., Putra, S., \& Puger, W. (2014). PENAMPILAN REPRODUKSI SAPI BALI PADA SISTEM TIGA STRATA. Jurnal Kedokteran Hewan - Indonesian Journal of Veterinary Sciences. https://doi.org/10.21157/j.ked.hewan.v8i1.1262

Pertumbuhan Dimensi Tinggi Tubuh Pedet Sapi Bali. (2014). Buletin Veteriner Udayana.

Putra, R. A., \& Hendrita, V. (2019). Kajian Sistem Pengelolaan Usaha Peternakan Sapi Potong di Kabupaten Sijunjung. Journal of Livestock and Animal Health. https://doi.org/10.32530/jlah.v2i2.186

Putra, T. G. (2016). Kualitas bibit sapi Bali pada kelompok tani ternak 'sejahtera' (penerima bantuan program penyelamatan betina produktif) di kampung Kalisemen distrik Nabire Barat kabupaten Nabire. Jurnal Agroforestri.

Zurahmah, N., \& The, E. (2012). PENDUGAAN BOBOT BADAN CALON PEJANTAN SAPI BALI MENGGUNAKAN DIMENSI UKURAN TUBUH. Buletin Peternakan. https://doi.org/10.21059/buletinpeternak.v35i3.1088 